\title{
The Syntax of Direct Object Mutation in Welsh
}

\author{
IAN ROBERTS
}

University of Stuttgart

\section{INTRODUCTION}

Initial consonant mutation (ICM henceforth) is a well-known feature of the Celtic languages. Welsh is unique among these languages in showing a case of ICM which is apparently not triggered by a specific lexical item. This is the direct object mutation (DOM). DOM applies exactly where the finite main verb moves to a pre-subject position (on this kind of verb movement, see Emonds 1980; Sproat 1985). On the other hand, where an auxiliary appears initially and the main verb is realised in a non-finite form known as the verbal noun occupying a position in between the subject and the object, there is no DOM. This is illustrated in (1) (in examples illustrating ICM, the mutated word is underlined and its citation form is given in parentheses after the example):

(1) a. Mi welodd Megan blant. (plant)

PRT saw Megan children

'Megan saw children.'

b. Mae Megan wedi gweld plant.

Is Megan ASP see children.

'Megan has seen children.'

In (1a) the word for "children" undergoes mutation from plant to blant (see Table 1 for a list of the mutations).

This article aims to propose an analysis of DOM and ICM which integrates these striking phenomena with what is known generally regarding phonosyntactic processes, functional heads and parametric variation. To the extent that it is

I would like to thank Robert Borsley, Siobhán Cottell, Pamela MacDonald, Anna Roussou, Heloisa Salles, Eithne Guilfoyle and two anonymous reviewers for $C J L$, as well as the audiences at the Celtic Syntax Seminar and the Fifth Welsh Syntax Seminar, both in Bangor, at the Second Comparative Celtic Syntax Conference (University College Dublin), and at the University of Geneva. Finally, my thanks to Susan Clack and Mari Eluned Williams for help with the data. 
successful, the analysis proposed below can thus be thought of as genuinely explanatory.

I will argue that DOM is a phonological reflex of $\mathrm{Agr}_{\mathrm{O}}$, and hence-plausibly - of accusative Case. I adopt the framework for parametric variation put forward by Roberts and Roussou (1997a, 1997b), which replaces the standard minimalist checking theory with the notion of PF-interpretation. I will show that the phenomenon of mutation can be naturally characterised in these terms, integrating this phenomenon into a general theory of morphosyntactic variation.

In order to understand the nature of mutation, it is necessary to introduce a framework for discussing the nature of the parametric options that are available to heads. ${ }^{1}$ One obvious feature that functional heads have is that they are able to attract or repel other heads. Roberts and Roussou (R\&R) reformulate checking theory in such a way as to give expression to the idea that movement and the associated cross-linguistic variation and morphophonological properties are reflexes of a single property of the computational component of the language faculty, a property which is driven by the interfaces. $R \& R$ refer to this property as interface interpretability. They adopt the standard view of the interfaces as PF and LF (i.e., the interfaces with the Articulatory-Perceptual and the ConceptualIntentional systems respectively) and take interpretability to be the property of mapping a syntactic feature onto a PF or LF expression. To illustrate with a very simple example, the noun table maps onto a PF representation (/teibl/) and

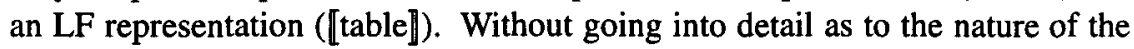
PF or LF representations, it suffices to state quite simply that, in principle, any syntactic symbol may or may not be mapped into a PF representation or to an LF representation. The lexicon provides the information determining the mapping.

Parametrisation is seen as the random assignment of a diacritic, written *, to features of functional heads. $F^{*}$ is similar, but not identical, to the standard notion of "strong feature". Where the diacritic is assigned to a feature, that feature, $\mathrm{F}^{*}$, must have a $\mathrm{PF}$ realisation (this is one difference between $\mathrm{R} \& \mathrm{R}$ 's system and Chomsky's; Chomsky 1995:233 explicitly disavows a link between feature strength and morphophonological realisation). This realisation can be achieved by the standard syntactic operations Move and Merge. Which option is taken depends on the lexicon, but the most economical is always preferred. For this reason, Merge is always preferred over Move. If the lexicon provides a phonological matrix for $\mathrm{F}^{*}$, then this matrix will be $\mathrm{F}^{*}$ 's realisation, and Move is unavailable. Conversely, if the lexicon has no phonological matrix for $\mathrm{F}^{*}$, material from elsewhere must be moved to $\mathrm{F}^{*}$ (subject to the usual constraints on movement). It is also possible

\footnotetext{
${ }^{1}$ Roberts and Roussou's approach also accounts for specifier-head relations, as one would require of a global alternative to checking theory. However, since this article is primarily concerned with head-head relations, I will not go into this aspect of Roberts and Roussou's system in detail here (but see the brief discussion of $w h$-movement and chain formation below).
} 
for $\mathrm{F}^{*}$ to be associated with a phonological matrix which is a syntactic affix, and which hence triggers both Move and Merge, following the Stray Affix Filter (or whatever constraint this is derived from). Simple examples of each of these options applying to the $\mathrm{Q}$ morpheme of yes/no-questions are given in (2).
a. Did he see Mary?
$Q^{*}$ Move
(English)
b. A welodd o Mary?
$\mathrm{Q}^{*}$ Merge
(Welsh)
c. A-t-il vu Marie?
(Literary French) $^{2}$
d. Il a vu Marie?
$\mathrm{Q}^{*}$ Move+Merge
(Colloquial French)

LF requirements may also induce overt movement. For example, in English wh-questions wh-C is *, giving rise to $\mathrm{T}$-to-C movement (as in yes/no questions like (2a)), but this movement alone does not suffice to identify a wh-dependency (since the head moved to $\mathrm{C}$ does not contain an overt WH-feature). In order to identify the $w h$-dependency, a $w h$-XP moves to [Spec, CP]; identification is carried out by formation of a simple dependency in the sense of Manzini (1994, 1995). Manzini (1995:328ff.) defines dependencies as a relation between a pair of categories (or features) $\alpha$ and $\beta$, such that (a) the dependency $(\alpha, \beta)$ has a well-formed interpretation, (b) $\alpha$ asymmetrically c-commands $\beta$, (c) there is no $\gamma$ which asymmetrically $\mathrm{c}$-commands $\beta$ and is asymmetrically $\mathrm{c}$-commanded by $\alpha$. Dependencies can compose just where the foot of one is the head of the next (i.e., if $(\alpha, \beta)$ and $(\gamma, \delta)$ are dependencies and $\beta=\gamma$, then $(\alpha, \beta, \gamma)$ is a composed dependency). $w h-\mathrm{XP}$ and $w h-\mathrm{C}$ have a well-formed interpretation as a wh-operator because the $w h-\mathrm{XP}$ in the specifier position asymmetrically and minimally c-commands the wh-C. Hence these elements can enter into a dependency. ${ }^{3}$ This analysis correctly predicts that languages with dedicated $w h$ particles lack wh-XPs and $w h$-movement (Cheng 1990:30), as here $Q^{*}$ is satisfied under Merge of a morpheme which overtly realises WH.

In the agreement system, identification is driven by the $\theta$-criterion: $\phi$-features must associated with $\theta$-roles, and DPs bearing $\phi$-features identify Agr positions containing $\phi$-features. R\&R's approach can also account for well-known differences between English and French regarding verb movement of the kind discussed by Emonds (1978) and Pollock (1989) straightforwardly. French has $\mathrm{Agr}_{S}{ }^{*}{ }_{\text {Move }}$, while English doesn't. At first sight, it is not clear that the fact that English tense and agreement marking is overtly realised on $\mathrm{V}$ is consistent with the claim that English $\mathrm{Agr}_{\mathrm{S}}$ does not have a PF realisation. However, the important point is that

\footnotetext{
${ }^{2}$ Here I assume that the French "enclitic subject pronouns" $-t u,-t-i l,-t$-elle, etc. are syntactic affixes. See Friedemann (1995), Sportiche (1994) on this.

${ }^{3}$ It may seem that this view entails dropping Chomsky's (1995) uniformity condition on chains (all members of a chain must have the same $\mathrm{X}^{\prime}$-status). However, it is possible to view the spec-head dependency as a head-head dependency. Clearly it is the wh-feature associated with the D-position of the wh-DP with which the wh-C combines. We can regard the rest of the DP as pied-piped, again along the lines sketched in Chomsky (1995). In this way, the uniformity condition may be maintained.
} 
$\mathrm{Agr}_{S}$ (or T) itself is not phonologically realised in finite clauses with no auxiliary in English. As Pollock's evidence shows, the main verb remains in VP (or at least is not in $\mathrm{Agr}_{\mathrm{S}} / \mathrm{T}$ ). So the question becomes: how does tense/agreement marking appear on an unmoved verb in English, and what is the status of this marking if it is not a realisation of $\mathrm{Agr}_{\mathrm{S}} \mathrm{T}$ ?

To answer these questions, we apply the notion of dependency introduced above to the case where the subject is raised from [Spec, VP] to [Spec, $\operatorname{Agr}_{\mathbf{S}} \mathrm{P}$ ] (glossing over the functional structure in between $\mathrm{Agr}_{\mathrm{S}}$ and VP):

(3)

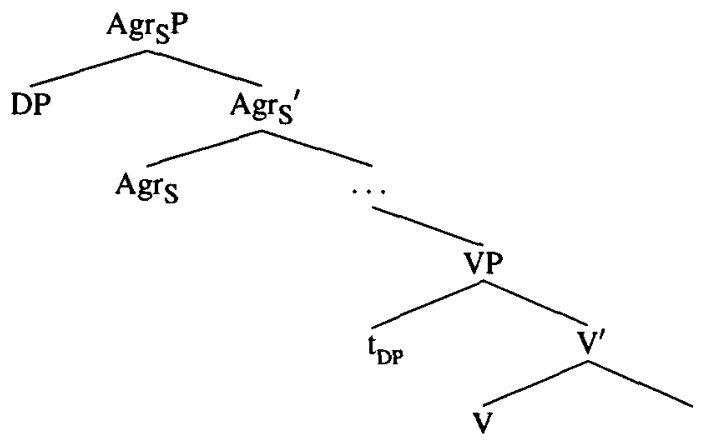

Let us assume that each V-related functional head enters into a dependency with the one it minimally asymmetrically c-commands (this is really the content of the notion of $\mathrm{V}$-relatedness). We thus have a complex dependency $\left(\mathrm{Agr}_{\mathrm{S}}, \ldots, \mathrm{V}\right)$. Moreover, $\mathrm{Agr}_{\mathrm{S}}$ also forms a dependency with the D head in its specifier (see note 3). These relations are illustrated in (4).

(4) a. D-Agrs

b. $\mathrm{Agr}_{\mathrm{S}}-\mathrm{T}-\ldots-\mathrm{V}$

c. $\mathrm{D}-\mathrm{Agr}_{\mathrm{S}}-\mathrm{T}-\ldots-\mathrm{V}$

The dependencies in (4a) and (4b) compose since the foot of the first forms the head of the next. So the subject forms a dependency with $V$ in (3). Hence, we have a way of connecting the subject to the verb (and thus of allowing the subject to satisfy the $\theta$-criterion). Since this dependency is headed by the $D$ subject we can regard the subject's $\phi$-features as features of this dependency. Since a single chain cannot contain contradictory features (i.e., both $[+F]$ and $[-\mathrm{F}]$ for some F), $\mathrm{Agr}_{\mathrm{S}}$ must bear the same features, or a subset of the subject's features - hence agreement. These features (or a subset of them) are realised on $\mathrm{V}$, giving rise to and licensing the overt agreement morpheme. We thus account for subject-verb agreement in English without recourse to downward V-movement, covert $\mathrm{V}$-movement, etc. This approach is consistent with the idea that features are properties of dependencies, since it is the latter that are interpretable. Moreover, no notions of checking are required. The prediction that $\mathrm{F}^{*}$ Merge disallows movement to $\mathrm{F}^{*}$ or its specifier is borne out in some northern Italian dialects, where we have 
$\operatorname{Agr}_{S}{ }^{*}{ }_{M e r g e}$, and subjects are unable to appear in [Spec, $\left.\operatorname{Agr}_{S} \mathrm{P}\right]$ (cf. Manzini and Savoia 1997). See R\&R for further details and applications of this system.

To summarise, $R \& R$ propose that the lexicon contains the following elements:

(5) a. lexical items, specified as $[ \pm V],[ \pm N]$, with $P F$ and $L F$ properties given;

b. features of functional heads;

c. * assigned in a language-particular fashion to (b).

The only variant property is the assignment of *. In these terms, "feature strength" reduces to PF-realisation and is cross-linguistically unpredictable because PF is cross-linguistically unpredictable.

Returning now to Welsh, the specific proposal that I would like to make about ICM is that certain mutations - including DOM - are the case of F* satisfied under Merge, where what is merged is a morpheme which consists wholly or partly of a floating phonological feature (in this respect, my analysis is similar to that of Lieber 1983). This feature is assigned to an adjacent category in a structural configuration to be defined below, giving rise to phonological effects in the assignee. This idea makes two important predictions: first, that where there is a mutation, there can be no movement; second, that mutation is sensitive to phonological constraints concerning linear adjacency, natural classes of sounds, etc. As we will see, both of these predictions are fulfilled.

With this background, we can proceed to the analysis of the mutations.

\section{An Initial Characterisation of the Context of ICM}

The phonological alternations which comprise ICM in Welsh are summarised in Table 1.

Table 1

. Initial consonant mutations in Welsh

\begin{tabular}{lllll}
\hline \hline Class & Root & Soft & Nasal & Aspirate \\
\hline -voice, -cont & $\mathrm{p}$ & $\mathrm{b}$ & $\mathrm{mh}$ & $\mathrm{f}$ \\
& $\mathrm{t}$ & $\mathrm{d}$ & $\mathrm{nh}$ & $\theta$ \\
& $\mathrm{k}$ & $\mathrm{g}$ & $\mathrm{gh}$ & $\mathrm{x}$ \\
& & $\rightarrow+$ voice & $\rightarrow$ +nas & $\rightarrow$ +cont \\
+voice, -cont & $\mathrm{b}$ & $\mathrm{v}$ & $\mathrm{m}$ & \\
& $\mathrm{d}$ & $\mathrm{\partial}$ & $\mathrm{n}$ & \\
& $\mathrm{g}$ & 0 & $\mathrm{~g}$ & \\
+son & & $\rightarrow+$ cont & $\rightarrow$ +nas \\
& $\mathrm{m}$ & $\mathrm{v} \rightarrow$-nas & & \\
& $\mathrm{t}$ & $\mathrm{l}$ & \\
\hline \hline
\end{tabular}


The system clearly has a certain phonological naturalness: soft mutation (or lenition) voices voiceless stops and makes voiced stops into the corresponding fricatives, as such it is a fairly standard case of consonant gradation with the single unexpected case of deletion of $/ g /$ instead of the expected conversion to $[\gamma]$ (which exists in Breton as the soft mutation of $/ \mathrm{g} /$ ). Its effects on sonorants are less regular, in that $/ \mathrm{m} /$ is converted to $/ \mathrm{v} /$, while voiceless liquids are voiced. The nasal and aspirate mutations are essentially regular. I write soft mutation as $L$ (aspirate mutation is written $H$ and nasal $N$ ).

What are the syntactic environments of ICM? It is a pervasive process in Welsh, but some generalisations can be made. First, ICM is characteristic of the complements of prepositions. Some Ps take soft mutation, some aspirate and one triggers nasal mutation:
a. i Fangor (Bangor) to Bangor
b. ym Mangor (Bangor) in Bangor
c. gyda chyfarchion
(cyfarchion) with compliments

Which $P$ triggers which mutation is clearly a lexical matter - we have to indicate this in the lexical entry of a given $\mathrm{P}$, so the lexical entry of $i$ is $i L$, that of $y n$ is $y n N$, and that of gyda is gydaH. The elements $L, N$ and $H$ are as much a part of the lexical entries of these prepositions as the segmental structure, and just as unpredictable. Non-mutation is also an option, and so part of the ICM paradigm; ger 'near' is a $\mathrm{P}$ which does not trigger ICM:

(7) ger Bangor near Bangor

The syntactic context of ICM triggered by a preposition is:

(8)<smiles>P[PH2]P</smiles>

Another context of ICM is following a determiner:

(9) a. pa/un/y ferch (merch) which/one/the girl
b. dau fachgen (bachgen) two boy
c. ei gar/char (car)
his/her car

(See Roberts and Shlonsky 1996:186 for justification of the idea that possessive pronouns like $e i$ in (9c) are in D). Note that the interpretation of the $3 \mathrm{sg}$ possessive 
pronoun depends on the mutation it triggers: the masculine pronoun triggers soft mutation while the feminine triggers aspirate mutation (i.e., $e i L$ is 'his' and $e i H$ is 'her'). So (10) is a further syntactic context of ICM.

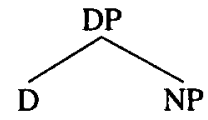

Third, pre-adjectival intensifiers can trigger mutation:
(11) $\mathrm{rhy} / \mathrm{pur} / \mathrm{mor}$ wyn
very/too/so white
(gwyn)

On analogy with what is known about the functional structures associated with verbs and nouns, we might suppose that there is a functional projection ModP associated with AP. Assuming further that intensifiers occupy the head position Mod, we then have the following structure for (11):

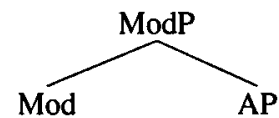

Fourth, clause-introducing particles trigger mutation (negative particles trigger "mixed mutation", which is the aspirate mutation where possible - i.e., where the initial consonant of the mutated word is a voiceless stop - and the soft mutation elsewhere):

(13) a. (Fe/mi) welais i plant. (gweld) (PRT) saw I children 'I saw children.'

b. Pwy a welith Gwilym? (gweld) Who PRT will-see Gwilym?

'Who will see Gwilym?'

c. (Nid) welais i ddim plant. (gweld) (NEG) saw I NEG children 'I didn't see children.'

The particle is frequently not pronounced but the mutation remains, indicating that the particle is subject to a late deletion rule in PF. It is reasonable to think that the particles are in C. So the ICM configuration is as follows:

(14)

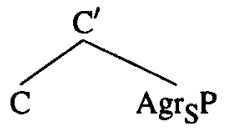

The contexts in (8), (10), (12), and (14) can clearly be generalised as follows:

(15) Mutation regularly affects the leftmost consonant in XP (when this consonant is [-cont] or [+son]) in the configuration: 


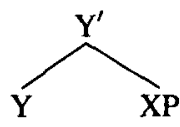

where $\mathrm{Y}$ is a mutation trigger.

In other words, the floating autosegment associated with $Y$ attaches to the left edge of XP and is phonologically realised where possible (i.e., where the phonological conditions permit). This operation takes place under linear adjacency and is subject to phonological conditioning, as reference to distinctive features in (15) shows. I take it, then, that this operation is a PF-operation, part of the operation of spell-out of mutation triggers.

The syntactic configuration in (15) could be characterised as head government. This conclusion parallels that of Rizzi and Savoia (1991), who show that /u/-propagation in various Southern Italian dialects is subject to a government condition. The precise nature of the government restriction varies from dialect to dialect, but one relevant parameter is F-government, government by functional head. If we take prepositions to be functional heads, then the Welsh mutation environments fall under this characterisation. Rizzi and Savoia also argue that the environments of obligatory liaison in French, analysed in terms of c-command by Manzini (1983), can be characterised in terms of head government. Also, Cardinaletti (1991) shows that /s/-affrication in Central Italian is sensitive to a similar restriction.

So we observe that the head-government relation in (15) is thus clearly relevant to phonosyntactic processes; this is a clear empirical generalisation. The theoretical question is: can we reduce the head-government relation to something else, if we want to adopt a theory which eschews head government as a primitive relation? R\&R's framework, as sketched above, affords a simple way of doing this. In terms of this framework, $\mathrm{Y}=\mathrm{F}^{*}{ }_{\text {Merge }}$, where the morpheme merged under $F^{*}$ contains a floating autosegment which must attach immediately to the right of Y. It follows that this element will attach to something in XP, including possibly [Spec, XP]. This gives rise to the effect of head government. It may be, then, that the effect of head government can be reduced to phonological properties of the putatively governing head. A more conservative conclusion is that the configurational relation of head government is relevant in PF, as argued by Aoun et al. (1987). I will not decide between these two positions here; further work, both on phonosyntax and on the residue of head government, is needed.

In the examples we have looked at so far, the mutation trigger has further segmental structure in addition to the floating feature which gives rise to ICM. Since the mutation trigger is a functional head, we can see this as a case of $\mathrm{F}^{*}{ }_{\text {Merge }}$ of a morpheme which happens to end in a floating feature. In that case, movement to $F^{*}$ is blocked by Economy, as we sketched above. This implies that ICM in general precludes movement. If this is so, then we expect that ICM will not be found in the context in (16), where $\mathrm{Y}$ is the trigger and XP undergoes ICM: 
(16)

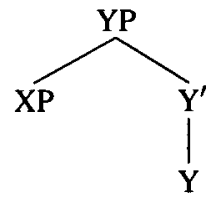

That is, we will never find a mutated category in the specifier of a mutationtrigger head. In fact, if we follow Kayne (1994) in assuming that all languages are underlyingly head-initial, with head-final orders being derived by movement, then it follows that mutation cannot be a property of non-head-initial languages/structures. We thus relate the fact that mutation is found in Celtic languages to the fact that they are rigidly head-initial. Moreover, I know of no head-final language with mutation. ${ }^{4}$ (Of course, this does not explain why mutation is found in just the subset of head-initial languages where we see it; beyond stating the obvious fact that languages differ in their segment inventories, I have nothing to say on this matter.)

So my basic claim about ICM is that it is a manifestation of $\mathrm{F}^{*}{ }_{\text {Merge }}$, where the merged element contains a floating autosegment which attaches to the left of a following category. Nothing in principle prevents this autosegment from being the sole content of the relevant morpheme. This is the case of direct object mutation, as I will propose in the next section (this was also proposed by Lieber 1983).

\section{Direct Object Mutation: The Evidence and Some Proposals}

The most striking example of ICM from a syntactic point of view is the DOM. As mentioned in the introduction, this mutation arises on direct objects (and other constituents - see below) when the verb is fronted. DOM is illustrated in (17a), while (17b) shows that it does not arise in periphrastic tenses where $V$ is not fronted.
a. Mi welodd Megan blant. (plant) PRT saw Megan children 'Megan saw children.'
b. Mae Megan wedi gweld plant. is Megan ASP see children. 'Megan has seen children.'

Lieber (1983) proposed that DOM is a manifestation of an empty P, which is inserted when V-movement destroys Case adjacency (cf. of-insertion in early versions of GB theory such as Stowell 1981). Harlow (1989:294ff.) argues against

\footnotetext{
${ }^{4}$ Brown (n.d.) describes the mutation system of Nias, a western Malayo-Polynesian VOS language spoken in north-central Sumatra. Another language known to have a mutation system similar to what we find in Celtic is Fula, which is SVO. Note also that the phonosyntactic phenomena discussed by Rizzi and Savoia (1991) and Cardinaletti (1991) are found in SVO Romance languages.
} 
this approach by pointing out that mutated direct objects do not behave like PPs under extraction. Clear cases of extraction of the complement of a $P$ have two possible manifestations in Welsh, in that $\mathrm{P}$ can be pied-piped or apparently stranded. Where $\mathbf{P}$ is stranded, it must agree in person and number with the complement. These options are illustrated by the following examples taken from Harlow (1989:294):
a. I bwy y rhoddodd y dyn anrheg t? (pwy) to whom PRT gave the man present 'To whom did the man give a present?'
b. Pwy y rhoddodd y dyn anrheg iddo? who PRT gave the man present to+3SG 'Who did the man give a present to?'

There are two important things about (18). First, as (18a) shows, a wh-word in a pied-piped constituent undergoes the mutation triggered by the $\mathrm{P}$, while a $w h$-word which apparently strands the $P$ does not. Second, the particle in $C$ is $y$. Now, when a direct object is extracted, the wh-word cannot mutate and the particle is always $a:^{5}$

(19) Pwy/*bwy a/*y welodd Megan?

Who PRT saw Megan

'Who did Megan see?'

If the mutated direct object were in a PP, then, other things being equal, we would expect pied-piping to be possible, and therefore expect the mutated form of the $w h$-word to be possible. Moreover, $y$ is the particle which usually occurs with extraction of or from PPs.

Harlow concludes that Lieber's analysis should be abandoned. Instead, he proposes that a constituent undergoes ICM when it is adjacent to and follows a DP. Borsley and Tallerman (1996) refine Harlow's generalisation by saying that a

${ }^{5}$ The examples in (19) apparently feature the Q-morpheme $a$ combined with a fronted wh-XP, which we said in section 2 was impossible. However, $a$ here is not a quantifier but a focus particle, in that it does not require the presence of a fronted $w h$-phrase, but is compatible with any DP:

(i) Gafr a welodd Gareth. goat PRT saw Gareth

'It was a goat that Gareth saw/It was the goat that saw Gareth.'

The same is true for $y$, where a PP is fronted:

(ii) Ym Mangor y siaradais i llynedd.

in Bangor PRT spoke I last-year

'It was in Bangor that I spoke last year.'

(Tallerman 1996:100)

Roberts and Roussou assume that focus particles differ from wh-particles in that they are not interpretable without being identified by a fronted XP (recall that identification involves formation of a simple dependency - see section 2). 
phrase bears soft mutation if it is immediately preceded by another phrase which c-commands it. The evidence for Borsley and Tallerman's conclusion comes from examples such as the following:
a. Mae yn yr ardd afr. (gafr) is in the garden goat "There's a goat in the garden.'
b. yr hen gi the old dog

In (20a), a PP is fronted in a locative/existential construction (cf. Rouveret 1996). Here, the DP $y r$ ardd does not c-command the mutated DP, but the PP yn yr ardd does. Example (20b) illustrates the fact that prenominal adjectives trigger mutation. In both of these cases, Borsley and Tallerman claim that the triggering category is a c-commanding XP which precedes the mutation target. ${ }^{6}$

Borsley and Tallerman seem to reach the correct empirical generalisation. It is clear, however, that the phenomenon remains unexplained on their account: it is entirely unclear why a phonological modification of a subclass of initial consonants of XP should take place exactly where XP is preceded and c-commanded by YP, where YP can be one of a range of categories. This kind of generalisation is unprecedented in terms of Case theory, checking theory, or any other theory of licensing that I am aware of. It also fails to relate DOM to southern Italian /u/propagation or French liaison, both of which appear to be configurationally similar phenomena. However, if we can reduce Borsley and Tallerman's generalisation to the general case illustrated in (16), we will at least have related DOM to the other instances of mutation and to the / $\mathrm{u} /$-propagation and liaison in a coherent way. I will now develop a proposal which does exactly this.

\section{Direct ObJeCt Mutation: An Alternative ANALYSIS}

My proposal for DOM is as follows:

(21) DOM is Agr ${ }^{*}$ Merge, where the merged element is the lenition-trigger $L$.

This clearly falls under the general proposal for ICM given in section 2. The relevant parts of the structure of a simple example like (16a) are as follows:

(22) $\ldots\left[_{\mathrm{Agr}_{\mathrm{O}} \mathrm{P}}\left[_{\mathrm{Agr}_{\mathrm{O}}} L\right]\left[\mathrm{vP}_{\mathrm{P}} \mathrm{t}_{\text {subj }} \mathrm{t}_{\mathrm{v}} \underline{\text { blant }]}\right]\right.$

Here $L$ has the effect of voicing the initial consonant of the object (citation form plant). This is because in the phonology it attaches to the first consonant to the right of $\mathrm{Agr}_{\mathrm{O}}$. The traces of the subject and the verb in VP are invisible to this $\mathrm{PF}$ process (if traces are copies which are deleted in PF, this implies that the copies are deleted prior to attachment of $L$ to the right; again, it is known that traces are

\footnotetext{
${ }^{6}$ Borsley (1996b) refines Borsley and Tallerman's approach, showing how making assumptions specific to the theory of Head-Driven Phrase Structure Grammar improves it.
} 
invisible to phonosyntactic processes in general, cf. Rizzi and Savoia 1991:289 and passim).

A couple of technical points need to be clarified in connection with (17a). In this kind of VSO sentence, the verb has clearly moved past $\mathrm{Agr}_{\mathrm{O}}$; $\mathrm{V}$ is in $\mathrm{Agr}_{\mathrm{S}}$ and the subject in [Spec, TP] in such cases (cf. also McCloskey 1996 on Irish). V also bears tense/agreement marking; -odd is the regular 3sg past ending. If $L$ is merged in $\mathrm{Agr}_{\mathrm{O}}$, how is it possible for $\mathrm{V}$ to move to this position, and from there into higher positions?

The answer to this question brings out certain technical aspects of R\&R's general approach that were left implicit in the presentation in section 2 . First, there is no Head Movement Constraint. The basic locality condition on dependency formation (minimal asymmetric c-command) has the same general effect, and to posit a separate constraint on movement would be redundant. Second, as a corollary of the first point, head movement is only cyclic to the extent that given heads are movement triggers. In Welsh, for example, as in French, finite $\mathrm{T}$ and $\mathrm{Agr}_{S}$ both trigger movement. The locality condition on movement is that the nearest available category which can satisfy the requirement for phonological realisation of the attractor moves. More precisely, the following is the definition of Attract (which is deliberately modelled on that given in Chomsky 1995:297):

(23) $\mathrm{F}^{*}$ Move attracts $\mathrm{H}$ if $\mathrm{H}$ is the closest head that can give a PF-interpretation to $\mathrm{F}$.

"Closeness" can be standardly defined as follows:

(24) $\beta$ is closer to $\mathrm{F}$ than $\alpha$ if $\mathrm{F}$ asymmetrically c-commands $\beta$ and $\beta$ asymmetrically c-commands $\alpha$.

These definitions allow for Move to "skip" intervening heads, just where these intervening heads are lacking in phonological content. However, this is not quite sufficient for the case at hand: $\operatorname{Agr}_{O}$ contains $L$, which is a kind of phonological content. There are two possible solutions here: either we state that a mere phonological feature is not sufficient content to satisfy $\mathrm{F}^{*}{ }_{\text {Move }}$, or we say that finite $\mathrm{Agr}_{\mathrm{S}}$ and/or $\mathrm{T}$ are syntactic affixes, requiring the affixation of a stem, and $L$ clearly is no stem. Of the two, the second solution seems more principled, and indeed has some independent motivation in Welsh (see Roberts and Shlonsky 1996). This solution also has the interesting consequence that we will see violations of the Head Movement Constraint (i.e., instances of overt head movement where one head "skips" another) in exactly the following case:

(25) $\mathrm{H}_{1}-\mathrm{Af} \ldots \mathrm{H}_{2} \ldots \mathrm{t}_{\mathrm{H} 1} \ldots$ where $\mathrm{H}_{1}$ can host Af and $\mathrm{H}_{2}$ cannot.

Interestingly, many cases of "long head movement" involving attachment of hosts to clitics are of this form (cf. Roberts 1994 and the references given there).

It is reasonable to think that $L$ is a manifestation of accusative features. In this respect, this account is rather similar to Lieber's. However, this analysis provides a straightforward account for the absence of DOM on extracted direct objects, which was Harlow's principal objection to Lieber's account, as we saw 
in the previous section. At the point of input to PF, (19) has a structure like the following:

(26) $\mathrm{Pwy} /$ * bwy a welodd Megan $\left[\mathrm{DP}_{\mathrm{wh}}\right.$ ]?

Quite simply, $L$ is unable to attach to the $w h$-trace here, for the same reason that it cannot attach to the trace of either the verb or the subject in (22). Still less can it attach to the $w h$-word $p w y$, as $L$ attaches at PF while $p w y$ moves in the syntax. A pied-piped $P$ triggers mutation in (18a).

Now let's look at the relevant parts of the structure of $(17 \mathrm{~b})$ :

(27) $\ldots$ [ $_{\mathrm{Agr}_{\mathrm{O}} \mathrm{P}} \mathrm{Agr}_{\mathrm{O}}$ [VP $\mathrm{t}$ gweld plant] ]

Here we do not have DOM, and we do not have V-movement. I assume for the sake of simplicity that the auxiliary bod (which suppletes as mae) is inserted in $\mathrm{T}$ and raises to $\mathrm{Agr}_{\mathrm{S}}$. This precludes $\mathrm{V}$-movement, by the locality conditions on Attract in (23)-(24). In compound tenses, $\mathrm{T}^{*}$ is satisfied under merger of an auxiliary, and $\mathrm{Agr}_{\mathrm{S}}{ }^{*}$ is satisfied by movement of that auxiliary. Here neither the non-finite verb nor the direct object are mutated. Following our account, even if $L$ encodes accusative Case, we expect it to be realised on the leftmost element of VP, that is, on the non-finite verb, giving weld rather than gweld. The fact that we do not see this implies that $L$ is not present. If $L$ is not present, $\mathrm{Agr}_{\mathrm{O}}$ presumably has no PF-realisation property (as we see no particle, affix, or V-movement). But, if $L$ is a realisation of accusative Case, and if it is indeed absent, what is the Case property of the direct object here?

An answer to the above question emerges if we consider what happens when the object is pronominal, as in (28), which has the partial structure in (29).

(28) Mae Megan wedi ei weld (o).

is Megan ASP 3SG see 3sG(echo pronoun)

'Megan has seen him.'

(29) $\ldots\left[\left[_{\mathrm{Agr}_{\mathrm{O}}} \mathrm{P}_{\mathrm{AgrO}_{\mathrm{O}}}\right.\right.$ ei] [VP $\mathrm{t}_{\mathbf{i}}$ weld (o)]]

As in (27), there is no $\mathrm{V}$-movement in (28). $\mathrm{Agr}_{\mathrm{O}}$ is occupied by a pronominal agreement morpheme with properties comparable to those of the subject agreement found on finite verbs; in particular it is associated with an optional echo pronoun (see Roberts and Shlonsky 1996 for more discussion of this point). So here a pronoun is merged into $\mathrm{Agr}_{\mathrm{O}}$, and $\mathrm{V}$-movement is blocked as in (27) (an auxiliary is merged in $\mathrm{T}$ and moved to $\mathrm{Agr}_{\mathrm{S}}$ ). What about $\mathrm{Agr}_{\mathrm{O}}$ 's accusative Case here? There is in fact some reason to believe that $\mathrm{Agr}_{\mathrm{O}}$ is not accusative but genitive in (28). The form of the pronoun is homophonous with the possessive pronouns. In fact, the paradigm for object pronouns with non-finite verbs (i.e., verbal nouns) is identical to that for possessive pronouns, as (30) shows. 
(30)

a. Possessive pronouns:

$\begin{array}{ll}\text { fy nghar (i) } & \text { 'my car' } \\ \text { dy gar (di) } & \text { 'your (sg) car' } \\ \text { ei gar (o) } & \text { 'his car' } \\ \text { ei char (hi) } & \text { 'her car' } \\ \text { ein car (ni) } & \text { 'our car' } \\ \text { eich car (chi) } & \text { 'your (pl) car' } \\ \text { eu car (nhw) } & \text { 'their car' }\end{array}$

b. Object pronouns with verbal noun:

$\begin{array}{ll}\text { fy ngweld (i) } & \text { 'see me' } \\ \text { dy weld (di) } & \text { 'see you (sg)' } \\ \text { ei weld (o) } & \text { 'see him' } \\ \text { ei gweld (hi) } & \text { 'see her' } \\ \text { ein gweld (ni) } & \text { 'see us' } \\ \text { eich gweld (chi) } & \text { 'see you (pl)' } \\ \text { ein gweld (nhw) } & \text { 'see them' }\end{array}$

Since there is no doubt that possessive pronouns in (30a) are genitive, it is natural to conclude that the object pronouns in (30b) are likewise genitive. This suggests that the direct object in (28) may also be genitive.

In fact, there is an interesting general parallel between VPs containing verbal nouns and DPs containing a possessive construction. ${ }^{7}$ Roberts and Shlonsky (1996:186) observe that the possessive pronoun blocks $\mathrm{N}$-to-D movement in possessives in a way which parallels the blocking of V-movement in clauses. This can be seen from the fact that where there is a fully nominal possessor the order is always possessed-possessor but possessive $e i$ always precedes the possessed nominal:

$$
\begin{aligned}
& \text { a. car John 'John's car' } \\
& \text { b. ei gar 'his car' }
\end{aligned}
$$

Example (31a) is a construct state, of a type familiar from studies of Semitic languages (see Borer 1981; Ritter 1988; Siloni 1991, 1994; Longobardi 1995). Here we have $D^{*}$ Move. In $(31 \mathrm{~b})$, on the other hand, we have $D^{*}{ }_{\text {Merge, where }}$ an $e i$-pronoun is merged. It is reasonable to see the $e i$-pronouns as the general realisation of genitive combined with $\phi$-features.

If the object is indeed genitive in (28), then the fact that it is not mutated can be related to the fact that possessed DPs do not mutate (they undergo various mutations when the possessor is pronominal, but these are triggered by the pronoun's $\phi$-features, as is clear from (30)). Given the proposal that DOM is a realisation of accusative, this suggests, following Zwicky (1984), that non-mutation is a mark of genitive. ${ }^{8}$

\footnotetext{
${ }^{7}$ This parallel reflects the fact that historically the verbal noun is a full-fledged nominal construction - see Clack (1993) for a study of Middle Welsh verbal nouns. It has also led a number of researchers to posit that verbal nouns are a kind of nominalisation, notably Rouveret (1994). See Borsley (1996a) for arguments against this idea. I will assume, primarily for the sake of simplicity, that verbal nouns are in fact verbs.

${ }^{8}$ In constructs, the possessed noun must raise to $\mathrm{D}$ to realise genitive (cf. Longobardi 1995). To fully implement the parallel between genitive $\mathrm{D}$ and genitive $\mathrm{Agr}_{\mathrm{O}}$ we might think that the verbal noun is raised, and that the object occupies a specifier position. Thus, the structure associated with the verbal noun and its object would be as in (i):

(i) ${ }_{\mathrm{Agr}_{\mathrm{O}}} \mathrm{P}^{\left[\mathrm{Agr}_{\mathrm{O}}\right.}$ gweld $\left._{\mathbf{i}}\right]\left[\mathrm{VP}\right.$ draig $\left.\left.\left[\mathrm{V}_{\mathrm{i}} \mathrm{t}_{\mathrm{i}}\right]\right]\right]$

Regarding the position of the object in relation to the base position of the subject, we could follow the proposal in Chomsky (1995:305ff.) and take Agr $\mathrm{A}_{\mathrm{O}}$ to be the light verb $v$.
} 
This analysis has implications for four constructions in Welsh: negation, impersonal passives, clausal complements and copular clauses. I now briefly treat each one of these.

\subsection{Negation}

Negation is relevant in that the "adverbial" clausal negation (comparable in its position to French pas - see Rouveret 1994:132)(d)dim undergoes soft mutation in a fashion which looks suspiciously like DOM. This can be seen in (32).

(32) Gaeth Fred ddim wobr. got Fred NEG prize

'Fred didn't get a prize.'

(King 1993:22)

It is in fact possible that $(d)$ dim is a negative quantifier inside the object DP here. In that case, this example is unproblematic for our analysis of DOM; this is just a regular instance of the phenomenon. The same might be true in cases where $(d) d i m$ is followed by the preposition $o$ (obligatory with specific and definite nominals, at least in the North), as in (33).

(33) (Ni) ddarllenodd Emrys ddim o'r llyfr. (NEG) read Emrys NEG of-the book.

'Emrys didn't read the book.'

However, there are cases where (d)dim mutates which are clearly not connected to DOM. We can see this most clearly with unaccusatives and in examples with the order $(d)$ dim ei:

(34) a. Chyrhaeddodd y trên ddim yn hwyr. arrived the train NEG late

'The train didn't arrive late.'

b. Wnaeth Emrys ddim ei daro.

did Emrys NEG 3SGM hit

'Emrys didn't hit him.'

Following the standard analysis of unaccusatives (Burzio 1986), I assume that there is no accusative in (34a). And I have just proposed that there is no accusative in examples like (34b); the presence of ei marks the genitive Case here. Nevertheless, the mutation appears on $(d) d i m$. This suggests that the mutation of $(d) d i m$ is not (or not always) a case of DOM, that is, a realisation of accusative Case.

It is tempting to think that ddim is not mutated, but rather is the standard form of this element when it is used as an adverbial negation in a finite clause. Non-mutated dim appears in non-finite clauses or as a negative pronoun:
a. Dim ysmygu.
no smoking
'No smoking.'

\footnotetext{
$\mathrm{V}$, the verbal noun, raises to this position and the subject is generated in its specifier. I will not speculate further along these lines here, though.
} 
b. Wi'n gwybod dim.

am-I.PRT know nothing

'I know nothing.'

(King 1993:107)

(Compare (35b) with Dwi ddim yn gwybod (NEG-am-I NEG PRT know) 'I don't know'). So we could think that ddim is the form of negation found in finite clauses, and dim that in non-finite clauses. In that case, mutation would be (synchronically) irrelevant to $(d)$ dim.

However, this approach cannot be right because dim shows up in existentials and impersonal passives where there is no argumental subject and no overt expletive. The minimal contrast appears in existentials, where, at least colloquially, an overt expletive-like element yna 'there' optionally appears in subject position. Where yna appears, (d)dim must mutate; where it does not appear, (d)dim cannot mutate:

(36) a. Fydd dim dosbarth wythnos nesa.

will-be NEG class week next

b. Fydd yna ddim dosbarth wythnos nesa.

will-be there NEG class week next

'There won't be class next week.'

The immediate generalisation, as pointed out by King (1993:22-23), is that mutation occurs immediately after the subject. This is in fact a subcase of Borsley and Tallerman's generalisation discussed above. The natural way to make sense of this in terms of the general approach to ICM advocated here is to say that $\mathbf{T}$ triggers mutation of $(d)$ dim when it can license a subject in its specifier (i.e., when it is nominative, presumably; since $T$ does not overtly realise nominative, or subject agreement, this assumption does not conflict with R\&R's general assumptions as laid out in section 2). This captures King's generalisation, as long as we assume that there is no expletive pro in [Spec, TP] in examples like (36a) (in fact, since expletive pro has no PF or LF property, there is no reason to assume the existence of such an element in a minimalist approach). It is also consistent with the general idea that $T$ licenses Neg (see Zanuttini 1991), and that the mutation of $(d) d i m$ is a realisation of the licensing relation that holds between $T$ and NegP. $T$ and NegP stand in the usual structural relation for the realisation of mutation, in that NegP is the complement of T (see Pollock 1989; Laka 1990; Zanuttini 1991). This approach explicitly distinguishes mutation of $(d)$ dim from DOM.

This analysis implies that the structure of (34b) is as in (37).

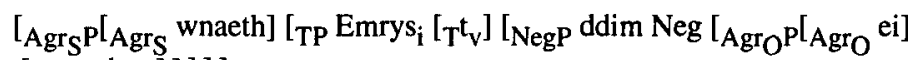

$$
\begin{aligned}
& \text { [VP } \left.\left.\left.\mathrm{t}_{\mathrm{i}} \text { daro] }\right]\right]\right] \text { ] }
\end{aligned}
$$

If (d)dim is not part of the direct object in examples like (33), then we have the same trigger for mutation of $(d) d i m$. It is tempting then to regard $o$ as a straightforward realisation of genitive, and to say that Welsh has an obligatory genitive of negation. However, we have to say something more, as the interaction 
of $o$ and $e i$-pronouns shows. This can be seen in negative periphrastic passives like (38).

(38) Chafodd y dyn ddim o 'i ladd. got the man NEG of 3SGM kill

'The man wasn't killed.'

Here there is no accusative available, since this is a passive. The order $o-e i$ (where $e i$ reduces phonologically to ' $i$ ) indicates that $o$ cannot simply be treated as DP-internal. For now, I propose that $o$ occupies $\operatorname{Agr}_{\mathrm{O}} \mathrm{P}$. So the structure of (38) is $(39):^{9}$

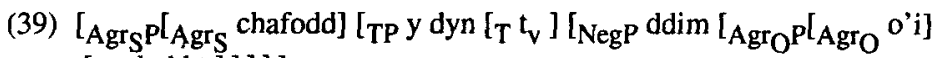
[vP ladd $\left.\left.\left.\left.t_{i}\right]\right]\right]\right]$ ]

In clauses with a simple tense, for example (32), if $(d) d i m$ is not inside the direct object, the presence of $o$ in $\mathrm{Agr}_{\mathrm{O}}$ may be what prevents the realisation of accusative, that is, what blocks DOM. ${ }^{10}$

Leaving aside these more speculative points, which can only be resolved by a detailed analysis of $(d) d i m$, we see that the mutation' of $(d) d i m$ is distinct from $\mathrm{DOM}$ and can be seen as a manifestation of the licensing of NegP by $\mathrm{T}$.

\subsection{Impersonal passives}

The next topic is impersonal passives. As we saw in section 3, Harlow (1989) proposed that a constituent undergoes DOM when it is adjacent to and follows a DP. This approach runs into problems in impersonal passive constructions, such as the following:

\footnotetext{
${ }^{9}$ Several complications are being glossed over here. First, there is the question of the representation of the logical subject of the passive, on which see Roberts (1987), Baker, Johnson and Roberts (1989). Second, I have ignored the question of cyclic movement of the object; there may well be intermediate traces of the object in some of the specifier positions. Third, I am assuming that cael is a passive auxiliary generated in T. Fourth, if the objects of verbal nouns are genitive, as proposed earlier, then one might wonder why the underlying object $y d y n$ has to move to subject position here. Case reasons cannot force this. An obvious suggestion would be that the Extended Projection Principle - whatever exactly that is - triggers movement here independently of Case considerations. However, the fact that there seems to be no subject-like element in either [Spec, TP] or [Spec, $\left.\operatorname{Agr}_{S} \mathrm{P}\right]$ in existentials like (36a), as we have just suggested, militates against this idea. This suggests that perhaps cael-passives should be treated as biclausal control structures. I cannot develop this idea further here, however.

${ }^{10} \mathrm{It}$ is in fact tempting to relabel $\mathrm{Agr}_{\mathrm{O}}$ as Aspect. This would then relate the accusative Case to a clearly LF-interpretable property. It is well-known that Asp interacts with the realisation of accusative Case cross-linguistically (see Benua and Borer 1996 for some recent proposals on this). However, in section 4.4, I will suggest that the two categories are in fact distinct.
} 
(40) Gwelwyd plant.

see-PASS children.

'Children were seen.'

Following the impersonal passive form of the verb, DOM is not found. One might think that this is because plant in (40) is in subject position, but it can be shown that this is not so. Plant can be cliticised by an infixed pronoun which can in turn be optionally doubled by an echo pronoun, and the impersonal passive can appear in a periphrastic tense where the single argument follows the verbal noun and so must be the direct object. These phenomena are illustrated in (41a) and (41b), respectively, taken from Harlow (1989:310). ${ }^{11}$

(41) a. Fe 'i gwelwyd (o).

PRT -him see-PASS (he)

'He was seen (him).'

b. Yr ydys yn gweld plant.

PRT is-PASS ASP see children

'Someone is seeing children.' (i.e., There is been seeing children.)

Harlow observes that his generalisation can be retained only if we assume that the subject is entirely absent in (41), that is, that the Extended Projection Principle doesn't hold (or doesn't hold in Welsh). The alternative would be to stipulate that expletive pro, as the only empty category that plausibly occupies the subject position in (41), does not trigger mutation on a following constituent. Nullsubject examples containing a referential null subject do trigger mutation, on the other hand:

(42) Mi welais pro $_{1 \mathrm{sg}}$ blant. (plant)

PRT saw-1SG children.

'I saw children.'

As mentioned in the previous section, expletive pro has no place in a truly minimalist theory (since it has neither PF nor LF properties). I therefore assume that [Spec, TP] is entirely absent in (41) (I leave aside the question of how - or if the EPP is satisfied in Welsh; for a suggestion see Roberts and Roussou 1997b). In that case, Harlow's analysis can stand.

What about the approach advocated here? This makes possible a very simple account of what is going on in impersonal passivs, one which relates the facts just seen to other well-known facts about passives (unlike Harlow's account). The structure of a simple impersonal passive like (40) is (43):

(43) $\left[{ }_{\mathrm{Agr} S} \mathrm{P}^{[\mathrm{Agr} S}\right.$ gwelwyd] $\left[\mathrm{TP}_{\mathrm{T}}\left[\mathrm{T}_{\mathrm{T}} \mathrm{t}_{\mathrm{V}}\right]\left[_{\mathrm{Agr}_{\mathrm{O}}}{ }\left[\mathrm{Agr}_{\mathrm{O}} \mathrm{t}_{\mathrm{V}}\right]\left[\mathrm{VP}_{\mathrm{V}} \mathrm{t}_{\mathrm{V}}\right.\right.\right.$ plant $\left.\left.\left.]\right]\right]\right]$

${ }^{11}$ These observations led Comrie (1977) to conclude that this construction violates the Motivated Chomage Law of relational grammar, in that it appears to be a case of "spontaneous demotion". 
Here, as in passives generally, $\operatorname{Agr}_{\mathrm{O}}$ 's Case feature is deactivated. ${ }^{12}$ Since accusative Case is unavailable, there is no DOM. The object is morphologically marked like the subject (i.e., there is no mutation). There is a straightforward parallel with Romance examples like (44), discussed by Belletti and Rizzi (1981) and Burzio (1986).

(44) $\mathrm{Ne}$ sono stati arrestati molti.

of-them are-3PL been-PL arrested-PL many-PL

'Many of them have been arrested.'

Whatever mechanism Case-licenses the object in (44) can Case-license plant in (43) (and the mechanism that takes away accusative in (44) can be operative in (43)). More interestingly, the fact that plant is not mutated, that is, is not accusative, in (43) emerges as an instance of Burzio's generalisation: the subject is suppressed and so the object cannot be accusative. ${ }^{13}$ What was a strange anomaly on Harlow's (1989) analysis is now seen as a reflex of a cross-linguistically robust generalisation (moreover, the account of Burzio's generalisation put forward in Baker, Johnson, and Roberts 1989:223 carries over, if we allow that Welsh -wyd corresponds to English -en, as hinted in footnote 12).

\subsection{Clausal complements}

Consider first non-finite clauses. Here we find that the non-finite verb form (the verbal noun, or VN henceforth) of embedded infinitivals undergoes soft mutation under conditions exactly comparable to DOM: where the main verb is finite it mutates, where there is no verb movement in the main clause it does not mutate. The following examples illustrate:

(45) a. Gall y dyn [XP ddreifio car]. (dreifio)

can the man drive car

'The man can drive a car.'

b. Mae'r dyn yn gallu [XP dreifio car].

is-the man in able drive car

'The man can drive a car.'

${ }^{12}$ See Chomsky (1981) and Burzio (1986). In terms of the analysis of passives put forward in Roberts (1987) and Baker, Johnson, and Roberts (1989), one could propose that the impersonal ending - wyd is incompatible with accusative Case.

${ }^{13}$ An anonymous reviewer points out that this analysis implies that the infixed pronoun in an example like (41a), repeated here as (i), cannot be a reflex of accusative Case:

(i) Fe 'i gwelwyd (o).

PRT -him see-PASS (he)

'He was seen (him).'

Instead, s/he points out, the condition on infixed pronouns must be like that on necliticisation, that is, internal argumenthood. This observation, which is correct as far as I can tell, further underpins the similarity between (i) and (44). 
Also like direct objects, the VN does not mutate when the entire embedded clause is fronted:

(46) [XP Dreifio car] (a) all y dyn. drive car (PRT) can the man

'It's drive a car that the man can.'

It is tempting to conclude from this that all non-finite clauses are in fact nominals, that is, that XP = DP here. In that case, we could extend our account of DOM to this data straightforwardly. However, Borsley (1996c) points out that in some kinds of complements VNs are possible but ordinary nominals are not:
a. Gobeithiodd Emrys [XP ddisgrifio 'r llun ]. (disgrifio) hoped Emrys describe(VN) the picture 'Emrys hoped to describe the picture.'
b. *Gobeithiodd Emrys [XP ddisgrifiad o'r llun ]. (disgrifiad) hoped Emrys description of-the picture

This seems to cast doubt on the idea that XP is DP in (45) and (46). Instead, I propose that XP is CP in these examples (this is also consistent with the idea that the VNs are not necessarily nominals - see note 7). In order to account for the mutation on the VNs here, I propose that $\mathrm{C}$ is filled by an empty preposition which Case-licenses the lower clause (this is presumably facilitated by dependency formation between $P$ and $V$ ). In this respect, my analysis of (45) and (46) parallels the analysis of English Exceptional Case Marking (ECM) in Kayne (1984) (with the exception that it is the lower clause rather than the lower subject which is Caselicensed). And in fact, Kayne's evidence for the Case-transmitting $\mathbf{P}$ is strikingly similar to the facts in (45) and (46): ${ }^{14}$

(48) a. We believe $\left[{ }_{C P}[P\right.$ e] John to be a genius].

b. ${ }^{*}$ It is believed $\left[_{C P}\left[_{P}\right.\right.$ e] John to be a genius].

\footnotetext{
${ }^{14}$ Two anonymous reviewers point out that the analysis of ECM assumed here is incompatible with Chomsky's (1995:272) proposals. Chomsky, following Lasnik and Saito (1991), proposes that the subject of the ECM clause is covertly raised into the higher clause for Case-checking. Although I do not assume covert movement for Case-checking here, the analysis proposed would not in fact be incompatible with this idea. Examples like (i) show that, on the kinds of assumptions that Chomsky makes in the quoted passage, a filled $C$ is no bar to covert raising of the infinitival subject.
}

(i) The parents arranged for the children to get presents at each other's parties.

Cf. also the rather clear evidence for overt raising of the subject of a non-finite clause in Postal (1974:154ff.):

(ii) He prevented there from being a riot.

In the absence of any account of complementiser-trace effects, subjects of complements are freely able to raise over prepositional and other complementisers. Hence Chomsky's proposals could be integrated with those made in the text. 
c. ${ }^{*}[\mathrm{CP}[\mathrm{P}$ e] John to be a genius], we believe.

As (48b) shows, the empty preposition can only transmit Case, it cannot originate it - so when the main verb is passivised and hence there is no accusative Case available, the presence of the preposition does nothing to save the structure. Example (48c) shows that the empty P must be head-governed by the main verb in order to transmit Case; fronting the complement clause removes $\mathbf{P}$ from this domain and so Case transmission becomes impossible (this, combined with the known strict-adjacency condition on ECM, suggests that this Case-licensing is a PF-phenomenon like DOM).

The structure of (45a) is given in (49):

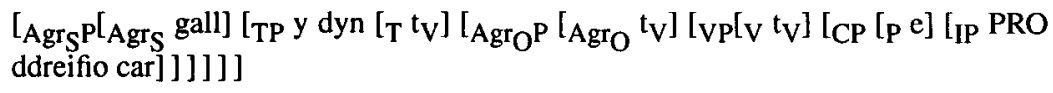

The empty prepositional complementiser transmits accusative from the matrix $\mathrm{Agr}_{\mathrm{O}}$ into the lower clause. Following the general analysis of DOM, the first consonant to the right of $P$ undergoes mutation if it can, hence the initial consonant of dreifio is mutated. P and IP are in the standard ICM configuration given in (15). In (45b), $\mathrm{Agr}_{\mathrm{O}}$ assigns genitive to V's complement (following the account of (17b) given above). This is also transmitted to the lower clause via the empty $P$. Examples (45) parallel the wh-movement examples we saw above (cf. (18)); the trace of the fronted XP does not contain a mutable consonant and so no mutation appears. ${ }^{15}$

\footnotetext{
${ }^{15} \mathrm{~A}$ similar analysis can be maintained where the main clause contains an indirect object, as in (examples from Borsley 1996c):

(i) Gorchmynodd i 'w fab ddychwelyd yn brydlon. (dychwelyd) ordered-3sG to his son return punctually 'He ordered his son to return punctually.'

(ii) Erfyniodd arnaf fynd gydag ef bob cam. (mynd) begged-3SG on-1sG go with he every step 'He begged me to go with him every step.'

(iii) Mae'n well ganddo fynd adref. (mynd) is ASP better with-3SGM go home 'He prefers to go home.'

A more problematic kind of example is the following (again due to Borsley 1996c), where the complement of $i$ is in subject position:

(iv) cyn i Megan fynd i Aberystwyth (mynd) before to Megan go to Aberystwyth 'before Megan went to Aberystwyth'

A possible analysis may be to treat the entire $i$-phrase as occupying subject position, with an empty prepositional complementiser (comparable to the with in English absolutive small clauses like With John going to Aberystwyth ... ):
} 
A further point concerns finite clauses. Many finite clauses are introduced by the fronted auxiliary bod (cf. Hendrick 1996, Rouveret 1996 for analyses of this element). This element also undergoes DOM in the same fashion as direct objects and non-finite clauses; when the verb raises, it shows DOM, and when the verb does not raise it does not:
a. Dywedodd Gwyn fod Emrys yn ddiog. (bod) said Gwyn be Emrys in lazy 'Gwyn said Emrys was lazy.'
(Borsley 1996c: 18)
b. Mae Alys yn dweud bod Aled ddim yn mynd allan. is Alys ASP say be Aled NEG ASP go out 'Alys says Aled is not going out.'
(Tallerman, to appear)

The above account of non-finite clauses carries over straightforwardly, supporting the idea that $L$ is assigned into the lower $\mathrm{C}$.

Finally, wh-complements provide interesting support for a head-government approach to DOM (or, more precisely, for the idea that there is a minimality condition on the assignment of $L$ ). Harlow (1989) pointed out that the initial $w h$ word of a $w h$-complement does not mutate (and recall that such words can mutate, as illustrated by $(18 \mathrm{a}))$ :

(51) a. Gwn i pa*kba lyfr i'w ddarllen.

know I which book to.3sGM read

'I know which book to read.'

b. Gwn i pwy/*bwy a ddaeth yn ôl.

know I who PRT came back

'I know who came back.'

(Borsley and Tallerman 1996:5)

We can assume that the $w h$-C (overtly realised as $a$ in (51b)) blocks head government of its specifier from outside CP by minimality. Hence $L$ cannot be assigned to the $w h$-words here. This favours a configurational rather than a linear approach to $L$-assignment, cf. the discussion at the end of section 2 .

\subsection{Locative/existential copular clauses}

Here we find that the subject of predication undergoes what looks like DOM if it is not adjacent to the copula:

(52) Mae yn yr ardd gi.

is in the garden dog

'There's a dog in the garden.'

(v) cyn [ ${ }_{\mathrm{CP}}[\mathrm{Pe}$ ] [IP [PP i Megan] fynd i Aberystwyth] ]

The mutation then proceeds as in the other examples under consideration here. The correctness of this analysis depends on the viability of the idea that the $i$-phrase is the subject. 
In his very detailed study, Rouveret (1996:134) proposes essentially the following underlying structure for locative/existential clauses:

$$
\begin{aligned}
& \text { [ }_{\mathrm{Agr}_{S} \mathrm{P}} \text { [TP }_{\mathrm{TPP}-1} \mathrm{CL} \text { [VP-2 }_{\mathrm{V}} \mathrm{ci} \text { [bod [PP yn yr ardd]]]1]] } \\
& \text { dog be in the garden }
\end{aligned}
$$

$C L$ here denotes a null locative clitic which bod incorporates. Leaving aside this and various other details of Rouveret's analysis, the most important point for my purposes is that three alternative derivations are available from an underlying structure like (53). On the one hand, $c i$ can move to [Spec, TP], PP remaining unmoved, and be licensed in the usual way for subjects, that is, with no mutation. This gives (54):

(54) Mae('r) ci yn yr ardd. is (the) dog in the garden

'The/a dog is in the garden.'

Alternatively, the expletive yna 'there' can be inserted in [Spec, TP], and neither gafr nor the PP move. In this situation, $c i$ fails to be licensed as a subject and instead receives accusative Case, and therefore shows DOM: ${ }^{16}$

(55) Mae yna gi yn yr ardd. (ci)

is there dog in the garden

'There's a dog in the garden.'

If $g i$ is VP-internal here, then our analysis of DOM can account for the mutation. However, examples like the following show that $g i$ is higher than the aspect particle, and hence, presumably higher than Asp and so outside VP (and higher than $\mathrm{Agr}_{\mathrm{O}}$ - see below):

(56) Mae yna ddyn yn siarad efo Mair. (dyn)

is there man ASP speak with Mary

'There is a man speaking with Mary.'

(Rouveret 1996:130)

For these cases, I take it that nominative $\mathrm{T}$ (i.e., $\mathrm{T}$ with a filled specifier) triggers DOM, as in the analysis of mutated ddim in 3.1. This is supported by the fact that mutation disappears in comparable examples where [Spec, TP] is empty: ${ }^{17}$

\footnotetext{
${ }^{16}$ A reviewer asks why Burzio's generalisation does not apply here, in other words why there is accusative Case when there is no external $\theta$-role. It seems that Burzio's generalisation applies to argument structures, and copular constructions do not have argument structure. Independent support for this idea comes from the fact that accusative clitics are available in Spanish copular constructions:

(i) Las hay en Chile. them have in Chile

'There are them (e.g., mountains) in Chile.'

${ }^{17}$ Of course, many examples of DOM of the general kind in (17a) could be attributed to nominative $\mathrm{T}$, rather than accusative $\mathrm{Agr}_{\mathrm{O}}$. However, adverbs can appear between the subject and the object, in a position which must be lower than $\mathrm{T}$ if the subject is in [Spec,
} 
(57) Does dim tywydd garw wedi bod ers misoedd. NEG-is NEG weather bad ASP be since months

'There has been no bad weather for months.'

(King 1993:163)

The third possible derivation from (53) involves raising of the PP, to give (52). Here again, ci undergoes DOM. It might appear that PP goes to [Spec, TP] here, but Rouveret shows that this is not the case, since the PP must follow (d)dim in the negative version of (52). In order for $c i$ to be able to be the attachment target for $L$, the PP must be higher than $\mathrm{Agr}_{\mathrm{O}}$. Following our general assumptions (see section 2), the PP cannot move to [Spec, $\operatorname{Agr}_{\mathrm{O}} \mathrm{P}$ ], as movement to the specifier of a category whose head overtly realises that category's feature content is not allowed (in this case, $L$ realises accusative Case). I conclude that Rouveret's abstract clitic heads a VP-external category (contra the representation in (53)), into whose specifier PP moves. If this category is situated higher than $\mathrm{Agr}_{\mathrm{O}}$, then we can retain the general account of DOM for (52). I suggest that this category is AspP. ${ }^{18}$

Finally, Borsley (1996c) points out the following alternation, involving different possible positions for the Experiencer PP of a psych-predicate:

a. Mae chwant arnaf i fynd adraf. (mynd) is desire on.1SG I go home

'I want to go home.'

TP] (and adverb adjunction to $\mathrm{T}^{\prime}$ is not allowed). In these cases, we have DOM under the usual conditions, and since DOM is subject to an adjacency constraint, it must be caused by $\mathrm{Agr}_{\mathrm{O}}$ and not $\mathrm{T}$ in these cases:

(i) Gwelais i yn sydyn blismyn yn y stryd. (plismyn) saw I suddenly policeman in the street

'I suddenly saw a policeman in the street.'

(Borsley and Tallerman 1996:8)

A related point concerns the lack of DOM on the VN after gwneud 'do' as in (ii).

(ii) Gwnaeth Emrys gweld/*weld Megan.

did Emrys see Megan

'Emrys saw Megan.'

If $\mathrm{VN}$ raises to $\mathrm{Agr}_{\mathrm{O}}$, as suggested in note 8, then we can understand why $\mathrm{Agr}_{\mathrm{O}}$ does not trigger DOM. However, why does nominative T not trigger it here? The answer must again be minimality: the intervening Asp head blocks assignment of $L$ from T. This does not happen in non-finite clauses like (49), since presumably Asp is inert in such clauses.

${ }^{18}$ Borsley (1996c) discusses one instance of DOM which may be relevant herenamely, DOM with apparently postposed objects in ditransitive constructions with the order IO > DO:

(i) Rhoddodd Emrys i Megan ddarlun o Gwyn. (darlun) gave Emrys to Megan picture of Gwyn 'Emrys gave a picture of Gwyn to Megan.'

Borsley points out that an analysis of ditransitives along the lines proposed by Larson (1988) can be appealed to here. 
b. Mae chwant mynd adraf arnaf i. is desire go home on.1SG I 'I want to go home.'

Here too, it may be that arnaf $i$ raises to [Spec, AspP] in the same manner as $y n$ yr ardd, and triggers DOM (realised inside the lower clause) in the same manner.

\section{CONCLUSION}

To conclude, we see that it is possible to maintain an interesting and insightful analysis of DOM. The central hypothesis, then, is that DOM is the PF-realisation of Agro's accusative Case as the floating feature $L$; in this we follow the basic insights of Lieber (1983) and Zwicky (1984).

The analysis proposed here has the following features:

a. it is an empirically adequate analysis of ICM in Welsh, which fully integrates DOM with the other cases of ICM;

b. it relates ICM to phonosyntactic processes found in other languages, notably Southern Italian /u/-propagation and French liaison;

c. it fits naturally into a non-checking-theoretic conception of parametric variation of the sort outlined in the introduction.

I submit that, because it has these features, this analysis takes us a step further towards a genuine understanding of ICM.

\section{REFERENCES}

Aoun, Joseph, Norbert Hornstein, David Lightfoot, and Amy Weinberg. 1987. Two types of locality. Linguistic Inquiry 18:537-579.

Baker, Mark, Kyle Johnson, and Ian Roberts. 1989. Passive Arguments Raised. Linguistic Inquiry 20: 219-251.

Belletti, Adriana, and Luigi Rizzi. 1981. The syntax of $n e$ : Some theoretical implications. The Linguistic Review 1:117-154.

Benua, Laura, and Hagit Borer. 1996. Passive/antipassive in a predicate-based approach to argument structure. Paper read at the GLOW Colloquium, Athens.

Borer, Hagit. 1981. Parametric variation in clitic constructions. Doctoral dissertation, Massachusetts Institute of Technology.

Borsley, Robert D. 1996a. On a nominal analysis of Welsh verb-nouns. Ms., University of Wales, Bangor.

Borsley, Robert D. 1996b. Mutation and constituent structure in Welsh. Ms., University of Wales, Bangor.

Borsley, Robert D. 1996c. Mutation and Case revisited. Paper read at the Fifth Welsh Syntax Seminar, University of Wales, Bangor.

Borsley, Robert D., and Maggie Tallerman. 1996. Phrases and soft mutation in Welsh. Journal of Celtic Linguistics 5:1-49. 
Brown, Lea. n.d. Nominal mutation in Nias. Ms., University of Sydney.

Burzio, Luigi. 1986. Italian syntax: A Government-Binding approach. Dordrecht: Kluwer.

Cardinaletti, Anna. 1991. The affrication of /s/ in a central Italian variety: Syntactic conditions on a "sandhi" rule. In Syntactic theory and the dialects of Italy, ed. Adriana Belletti, 99-129. Turin: Rosenberg and Sellier.

Cheng, Lisa. 1990. On the typology of $w h$-questions. Doctoral dissertation, Massachusetts Institute of Technology.

Chomsky, Noam. 1981. Lectures on government and binding. Dordrecht: Foris.

Chomsky, Noam. 1995. The Minimalist Program. Cambridge, Mass.: MIT Press.

Clack, Susan. 1993. Towards a more nominal verb-noun in Middle Welsh. Paper read at the Linguistics Association of Great Britain, Autumn Meeting, University of Wales, Bangor.

Comrie, Bernard. 1977. In defense of spontaneous demotion. In Syntax and semantics 8: Grammatical relations, ed. Peter Cole and Jerrold Sadock, 25-55. New York: Academic Press.

Emonds, Joseph. 1978. The verbal complex V-V' in French. Linguistic Inquiry 9:151-175.

Emonds, Joseph. 1980. Word order in generative grammar. Journal of Linguistic Research 1:33-54.

Friedemann, Marc-Ariel. 1995. Sujets syntaxiques : positions, inversion et pro. Doctoral dissertation, Université de Genève.

Harlow, Steve. 1989. The syntax of Welsh soft mutation. Natural Language and Linguistic Theory 7:289-316.

Hendrick, Randall. 1996. Some syntactic effects of suppletion in the Celtic copulas. In The syntax of the Celtic languages: A comparative perspective, ed. Robert D. Borsley and Ian Roberts, 75-96. Cambridge: Cambridge University Press.

Kayne, Richard S. 1984. Connectedness and binary branching. Dordrecht: Foris.

Kayne, Richard S. 1994. The antisymmetry of syntax. Cambridge, Mass.: MIT Press.

King, Gareth. 1993. Modern Welsh: A comprehensive grammar. London: Routledge.

Laka, Itziar. 1990. Negation in syntax: On the nature of functional categories and projections. Doctoral dissertation, Massachusetts Institute of Technology.

Larson, Richard. 1988. On the double object construction. Linguistic Inquiry 19:335-391.

Lasnik, Howard, and Mamoru Saito. 1991. On the subject of infinitives. In Papers from the 27th Regional Meeting of the Chicago Linguistic Society Part 1: The General Session, ed. Lise M. Dobrin, Lynn Nichols, and Rosa M. Rodriguez. Chicago Linguistic Society, University of Chicago.

Lieber, Rochelle. 1983. New developments in autosegmental morphology: Consonant mutation. In Proceedings of the West Coast Conference on Formal Linguistics 2, ed. Michael Barlow, Daniel P. Flickinger, and Michael T. Wescoat, 165-175. Stanford Linguistics Association, Stanford University.

Longobardi, Giuseppe. 1995. The syntax of genitive. Part one: Construct state across languages: Á minimalist interpretation. Ms., Università di Venezia.

Manzini, M. Rita. 1983. Syntactic conditions on phonological rules. In MIT Working Papers in Linguistics 5, ed. Isabelle Haik and Diane Massam, 1-9. Department of Linguistics and Philosophy, Massachusetts Institute of Technology.

Manzini, M. Rita. 1994. Locality, minimalism and parasitic gaps. Linguistic Inquiry 25:481-508. 
Manzini, M. Rita. 1995. From Merge and Move to form dependency. University College London Working Papers in Linguistics 7:323-346.

Manzini, M. Rita, and Leonardo Savoia. 1997. Parameters of subject inflection in a grammar without pro. Paper read at the Workshop on Subjects, Expletives and the EPP, Tromsø.

McCloskey, James. 1996. On the scope of verb movement in Irish. Natural Language and Linguistic Theory 14:47-104.

Pollock, Jean-Yves. 1989. Verb movement, UG and the structure of IP. Linguistic Inquiry 20:365-424.

Postal, Paul. 1974. On raising. Cambridge, Mass.: MIT Press.

Ritter, Elisabeth. 1988. A head-movement approach to construct-state noun phrases. Linguistics 26:909-929.

Rizzi, Luigi, and Leonardo Savoia. 1991. Conditions on / $\mathrm{u}$ propagation in southern Italian dialects: A locality parameter for phonosyntactic processes. In Syntactic theory and the dialects of Italy, ed. Adriana Belletti, 252-312. Turin: Rosenberg and Sellier.

Roberts, Ian. 1987. The representation of implicit and dethematized subjects. Dordrecht: Foris.

Roberts, Ian. 1994. Two types of head movement in Romance. In Verb movement, ed. David Lightfoot and Norbert Hornstein, 207-242. Cambridge: Cambridge University Press.

Roberts, Ian, and Anna Roussou. 1997a. Interface interpretation. Paper read at the 20th GLOW Colloquium, Rabat.

Roberts, Ian, and Anna Roussou. 1997b. The EPP as a condition on tense. Paper read at the Workshop on Subjects, Expletives and the EPP, Troms $\varnothing$.

Roberts, Ian, and Ur Shlonsky. 1996. Pronominal enclisis in VSO languages. In The syntax of the Celtic languages: A comparative perspective, ed. Robert D. Borsley and Ian Roberts, 171-199. Cambridge: Cambridge University Press.

Rouveret, Alain. 1994. Syntaxe du gallois : principes généraux et typologie. Paris: CNRS Éditions.

Rouveret, Alain. 1996. Bod in the present tense and in other tenses. In The syntax of the Celtic languages: A comparative perspective, ed. Robert D. Borsley and Ian Roberts, 125-170. Cambridge: Cambridge University Press.

Siloni, Tal. 1991. Noun raising and the structure of the noun phrase. In MIT Working Papers in Linguistics 14, ed. Jonathan D. Bobaljik and Tony Bures, 255-270. Department of Linguistics and Philosophy, Massachusetts Institute of Technology.

Siloni, Tal. 1994. Noun phrases and nominalizations. Doctoral dissertation, Université de Genève.

Sportiche, Dominique. 1994. Subject clitics in French and Romance: Complex inversion and clitic-doubling. Ms., University of California, Los Angeles.

Sproat, Richard. 1985. Welsh syntax and VSO structure. Natural Language and Linguistic Theory 3:173-216.

Stowell, Tim. 1981. The origins of phrase structure. Doctoral dissertation, Massachusetts Institute of Technology.

Tallerman, Maggie. 1996. Fronting constructions in Welsh. In The syntax of the Celtic languages: A comparative perspective, ed. Robert D. Borsley and Ian Roberts, 97-124. Cambridge: Cambridge University Press. 
Tallerman, Maggie. To appear. The uniform Case-licensing of subjects in Welsh. The Linguistic Review.

Zanuttini, Raffaella. 1991. Syntactic properties of sentential negation: A comparative study of Romance languages. Doctoral dissertation, University of Pennsylvania.

Zwicky, Arnold. 1984. Welsh soft mutation and the case of object NPs. In Papers from the Twentieth Regional Meeting of the Chicago Linguistic Society, ed. Joseph Drogo, Veena Mishra, and David Testen, 387-402. Chicago Linguistic Society, University of Chicago. 